\title{
Terpene synthases and their contribution to herbivore-induced volatile emission in western balsam poplar (Populus trichocarpa)
}

\author{
Sandra Irmisch¹, Yifan Jiang², Feng Chen², Jonathan Gershenzon ${ }^{1}$ and Tobias G Köllner ${ }^{1 *}$
}

\begin{abstract}
Background: As a response to caterpillar feeding, poplar releases a complex mixture of volatiles which comprises several classes of compounds. Poplar volatiles have been reported to function as signals in plant-insect interactions and intra- and inter-plant communication. Although the volatile blend is dominated by mono- and sesquiterpenes, there is much to be learned about their formation in poplar.

Results: Here we report the terpene synthase (TPS) gene family of western balsam poplar (Populus trichocarpa) consisting of 38 members. Eleven TPS genes (PTTPS5-15) could be isolated from gypsy moth (Lymantria dispar)-damaged P. trichocarpa leaves and heterologous expression in Escherichia coli revealed TPS activity for ten of the encoded enzymes. Analysis of TPS transcript abundance in herbivore-damaged leaves and undamaged control leaves showed that seven of the genes, PtTPS6, PtTPS7, PtTPS9, PtTPS10, PtTPS12, PtTPS13 and PtTPS15, were significantly upregulated after herbivory. Gypsy moth-feeding on individual leaves of $P$. trichocarpa trees resulted in induced volatile emission from damaged leaves, but not from undamaged adjacent leaves. Moreover, the concentration of jasmonic acid and its isoleucine conjugates as well as PtTPS6 gene expression were exclusively increased in the damaged leaves, suggesting that no systemic induction occurred within the tree.

Conclusions: Our data indicate that the formation of herbivore-induced volatile terpenes in P. trichocarpa is mainly regulated by transcript accumulation of multiple TPS genes and is likely mediated by jasmonates. The specific local emission of volatiles from herbivore-damaged leaves might help herbivore enemies to find their hosts or prey in the tree canopy.
\end{abstract}

Keywords: Populus trichocarpa, Sesquiterpenes, Monoterpenes, Volatiles, Terpene synthase gene family, Jasmonic acid

\section{Background}

Volatile organic compounds (VOCs) play multiple roles in the interactions of plants with their environment. Floral and fruit VOCs, for example, are known as attractants for pollinators and seed dispersers, respectively, while vegetative VOCs are reported to have various functions in inter- and intra-plant communication and plant defense against herbivores and pathogens $[1,2]$. The emission of VOCs from vegetative plant organs is often induced by biotic stresses like insect herbivory [3,4]. Such induced volatile blends can attract natural enemies of the herbivores, a reaction termed indirect defense [2]. For

\footnotetext{
* Correspondence: koellner@ice.mpg.de

${ }^{1}$ Max Planck Institute for Chemical Ecology, Hans-Knöll-Strasse 8, D-07745,

Jena, Germany

Full list of author information is available at the end of the article
}

example, the volatile blends from herbivore-infested Arabidopsis thaliana, black poplar (Populus nigra) and maize (Zea mays) have been described to be attractive for different parasitoids [5-7]. However, beside their role as signals in indirect defense, herbivore-induced vegetative VOCs can also function in direct defense as toxins and repellants for herbivores [8-10].

In general, herbivore-induced volatile blends are often dominated by terpenes but also comprise other classes of natural compounds including green leaf volatiles, alcohols, esters, and nitrogen-containing volatiles. Terpenes represent the largest and most diverse group of plant secondary metabolites [1]. They are built up of isoprenoid $\left(C_{5}\right)$ units which have their origin either in the mevalonate pathway or in the 2-C-methylerythritol-4-phosphate (MEP) pathway. A head to tail condensation of such $\mathrm{C}_{5}$ units 
catalyzed by prenyltransferases leads to the formation of geranyl diphosphate (GPP), farnesyl diphosphate (FPP), and geranylgeranyl diphosphate (GGPP). Terpene synthases (TPSs), the key enzymes of terpene metabolism, convert these precursors into the huge number of different terpene carbon skeletons [11]. Most plant genomes possess a midsize gene family encoding terpene synthases [12]. Based on their phylogenetic relationships, plant TPSs can be classified into seven different clades [12,13]. TPS-a, TPS-b and TPS-g are angiosperm-specific clades with the TPS-a clade containing predominantly sesquiterpene synthases and the TPS-b and TPS-g clades consisting mostly of monoterpene synthases. The TPS-d clade comprising mono-, sesqui- and diterpene synthases and the TPS-h clade comprising diterpene synthases are gymnosperm- and lycopod- (Selaginella moellendorfii) specific, respectively. The gymnosperm and angiosperm copalyl diphosphate synthases (CPS) and kaurene synthases (KS) make up the TPS-c and TPSe/f clades, respectively. Recently, a new class of terpene synthases was found in S. moellendorffii which showed sequence similarity to microbial terpene synthases and were designated as microbial terpene synthase like (MTPSL) genes [14].

While a few terpene synthases do function in plant primary metabolism, for example, in gibberellin biosynthesis, the majority functions in the biosynthesis of secondary metabolites involved in ecological interactions. Due to the prominent occurrence of terpenes in herbivore-induced volatile blends $[3,9,15]$, terpene synthases have received a lot of attention and much evidence exists for their involvement in plant defense. For example, the introduction of a sesquiterpene synthase gene from wild tomato (Solanum habrochaites) into a cultivated tomato line resulted in an increased herbivore resistance [16]. The overexpression of a linalool synthase in A. thaliana also increased the resistance of this plant against aphids [17]. Additionally, herbivory-induced terpene synthases from lima bean (Phaseolus lunatus) and maize, for example, are reported to produce sesquiterpenes which have been shown to attract natural enemies of insect herbivores $[18,19]$.

The majority of information about plant responses to herbivory is mainly based on herbaceous plants. However, in recent years an increasing number of studies on volatile-mediated plant defense have been carried out on woody species from both the gymnosperms and angiosperms. It is known, for example, that poplar emits a complex volatile blend after being damaged by herbivores $[7,10,20,21]$. Although monoterpenes and sesquiterpenes are described to be the most dominant compounds emitted, only 8 terpene synthase genes have been isolated and characterized from poplar to date. These include the isoprene synthase (IPS) from P. alba x P. tremula [22], PtdTPS1 from $P$. trichocarpa x $P$. deltoides [20], PnTPS1 and PnTPS2 from black poplar (P. nigra) [7] and four TPS (PtTPS1-4) from western balsam poplar
(P. trichocarpa) [21], the species of Populus that has been fully sequenced [23].

In this report we describe the identification and functional characterization of the TPS gene family of P. trichocarpa consisting of thirty-eight members. Fifteen TPS genes could be isolated from herbivore-damaged leaves, of which eleven have not been characterized before. A qRTPCR analysis revealed that the majority of these genes were upregulated after herbivory indicating their potential involvement in plant defense. To study the spatial regulation of herbivore-induced volatile biosynthesis in more detail, we carried out a comprehensive volatile collection from a single herbivore-infested leaf and from individual neighboring undamaged leaves and compared the observed volatile pattern with TPS gene expression data as well as with phytohormone levels in these tissues.

\section{Results}

\section{The TPS gene family in $P$. trichocarpa}

To identify the members of the TPS gene family in $P$. trichocarpa, we conducted a BLAST analysis using the second improved version of the poplar genome (v3 assembly, http://www.phytozome.net/poplar). This analysis revealed 38 full length TPS genes which encode for putative proteins with a minimal length of 520 amino acids including the previously published genes PtTPS1-4 [21] (Figure 1). Additionally, 19 TPS gene fragments were found in the database. Bacterial-like TPSs as already described for S. moellendorffii [14] were not identified in the poplar genome. Six of the seven TPS gene subfamilies were represented in the 38 complete poplar TPSs (Additional file 1: Figure S1) [12]. The TPS- $a$ subfamily with 16 members and the TPS- $b$ subfamily with 17 members made up the majority of poplar TPSs, while only two members each fell into the TPS- $g$, TPS-c and the TPS-e subfamilies and only one TPS gene clustered within the TPS $-f$ subfamily. As the members of the TPS$c$ and TPS-e subfamily most likely represent copalyl diphosphate synthases and kaurene synthases (for conserved protein sequence motifs see Additional file 1: Figure S2), respectively, which are not involved in volatile biosynthesis, we did not focus on these in more detail in this study. The chromosomal position was assigned to 29 of the full-length TPS genes, and these were found to be located on eleven of the nineteen poplar chromosomes. About one third of the TPS genes and half of the TPS gene fragments were found on chromosome 19, suggesting the occurrence of multiple duplication and recombination events on this chromosome (Additional file 1: Figure S3). On other chromosomes, a maximum number of three TPS genes were found. Nine TPS genes and 4TPS gene fragments were not linked to poplar chromosomes based on the new genome version. Many of these sequences share a high degree of nucleotide 


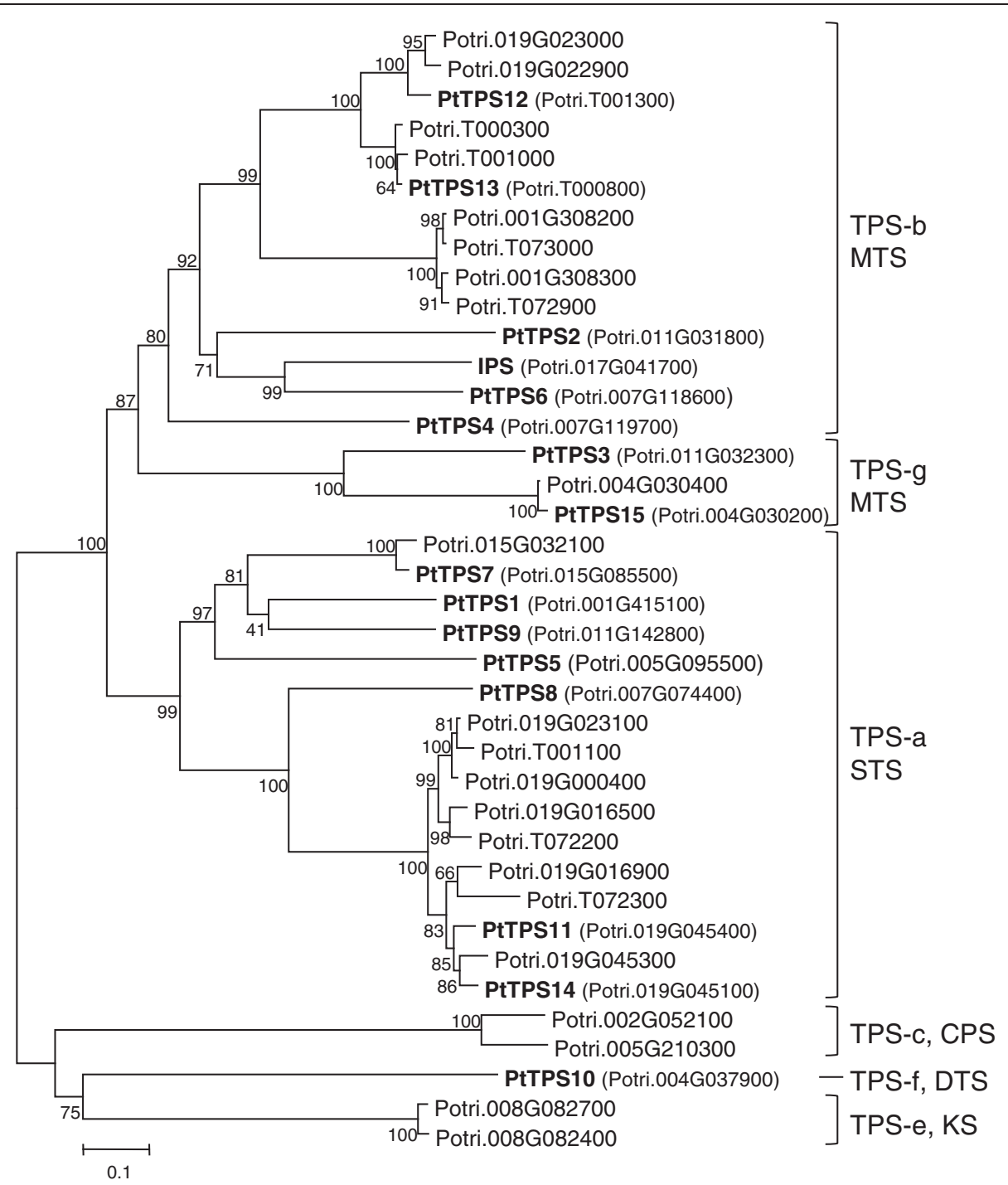

Figure 1 Phylogenetic tree of full-length terpene synthases (TPS) from Populus trichocarpa. The phylogenetic relationship of 38 P. trichocarpa TPS is shown. PtTPS1-4 and IPS have been characterized in previous studies. The tree was inferred with the neighbor-joining method and $n=1000$ replicates for bootstrapping. Bootstrap values are shown next to each node. IPS, isoprene synthase; STS, sesquiterpene synthase; MTS, monoterpene synthase; CDS, copalyl diphosphate synthase; DTS, diterpene synthase; KS, kaurene synthase. TPS-a to h represent TPS subfamilies.

identity which makes annotation and assignment in the genome difficult. Therefore one could still expect changes in the actual numbers of poplar TPS genes and their locations as newer versions of the poplar genome are released.

Isolation of poplar TPS genes and their structural features Using cDNA made from gypsy moth (Lymantria dispar)damaged $P$. trichocarpa leaves, 15 open reading frames of TPS genes could be amplified and cloned. Eleven of them represented poplar TPS genes which have not been characterized and described before. Following the nomenclature of Danner and coworkers (2011), the genes were designated as PtTPS5 to PtTPS15 (Figure 1). Based on their sequence similarity to so far characterized poplar TPS and representative TPS from other plant species (Additional file 1: Figure S4), the proteins encoded by PtTPS5-15 were tentatively classified as four monoterpene synthases (MTS) (PtTPS6, PtTPS12, PtTPS13, PtTPS15), six sesquiterpene synthases (STS) (PtTPS5, PtTPS7, PtTPS8, PtTPS9, PtTPS11, PtTPS14) and a diterpene synthase (DTS) (PtTPS10). PtTPS5-15 all had a length between 550 to 840 amino acids (Additional file 2: Table S1) and contained typical conserved elements including the DDxxD motif and the NSE/DTE motifs (Additional file 1: Figure S5), both of which are involved in the binding of the metal cofactor [24]. 
Interestingly, PtTPS11 and PtTPS14 possessed an altered NSE/DTE motif which contained a glycine residue instead of the serine/threonine. Another typical sequence motif, the RR $(\mathrm{x})_{8} \mathrm{~W}$ motif in the $\mathrm{N}$-terminal part was also changed and expressed as RP $(\mathrm{x})_{8} \mathrm{~W}$ in PtTPS11 and PtTPS14 and was completely absent in PtTPS15. Another conserved protein sequence of terpene synthases is the RxRmotif implicated in the complexation of the diphosphate group after ionization of the substrate [24]. In PtTPS15, the RxR motif was modified to $\mathrm{RxQ}$, which is also present in PtTPS3 [21]. TPS10, a putative diterpene synthase, showed an RxK motif at this position (Additional file 1: Figure S5, Additional file 2: Table S1).

In general, MTS and DTS contain N-terminal signal peptides which target these proteins to the plastids, the site of GPP and GGPP biosynthesis [13]. In contrast, sesquiterpene synthases are localized in the cytosol where FPP serves as the substrate for this enzyme class. The TargetP 1.1 server (http://www.cbs.dtu.dk/services/TargetP/) was used for signal peptide prediction. A plastid transit peptide was predicted for PtTPS6, PtTPS12 and PtTPS13 (Additional file 2: Table S1) supporting their roles as MTS in plastids. However, no signal peptide could be predicted for the putative MTS PtTPS15 and the putative DTS PtTPS10.

\section{Heterologous expression and in vitro functional characterization of poplar TPSs}

For functional characterization of poplar TPS, all isolated TPS genes were heterologously expressed in Escherichia coli. To ensure that the predicted signal peptides did not interfere with expression, truncated versions of PtTPS6

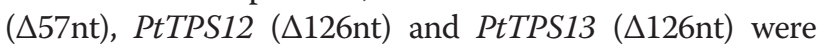
expressed. The truncations were chosen so that the $R R(x)$ ${ }_{8} \mathrm{~W}$-motif was still present. Proteins from raw extracts were assayed with GPP, FPP and GGPP, each in the presence of the co-substrate magnesium chloride, to determine monoterpene-, sesquiterpene- and diterpene- forming activity, respectively.

All putative MTS (PtTPS6, PtTPS12, PtTPS13 and PtTPS15) accepted GPP as substrate and produced monoterpenes (Figure 2B). PtTPS6 formed (E)- $\beta$-ocimene as the major product with minor amounts of $(Z)-\beta$-ocimene. A similar narrow product specificity could also be observed for PtTPS15, which produced only linalool, and PtTPS12 which formed linalool and trace amounts of $\beta$-phellandrene, (E)- $\beta$-ocimene and $\alpha$-terpinolene. However, PtTPS13 made five monoterpenes including $\alpha$-pinene, $\beta$-pinene, sabinene, 1,8-cineole and $\alpha$-terpineol. The incubation of PtTPS6 and PtTPS13 with FPP revealed no product formation. In contrast, PtTPS12 showed a broad sesquiterpene product spectrum and produced at least 25 different sesquiterpenes with $\gamma$-curcumene being the major one, and PtTPS15 was able to convert FPP to nerolidol (Figure 2A).
Four out of the 6 putative STS were able to convert FPP into different sesquiterpenes (Figure 2A). PtTPS9 produced $(E)$ - $\beta$-caryophyllene and smaller amounts of $\alpha$-humulene. In contrast, PtTPS11 showed a broader product spectrum comprising 18 different sesquiterpenes with $\beta$-elemene, eremophilene, $\alpha$-selinene and an unidentified sesquiterpene representing the major peaks. Such complex product spectra could also be observed for PtTPS5, producing at least 27 different sesquiterpenes dominated by an unidentified sesquiterpene alcohol, and for PtTPS7 producing more than 15 different sesquiterpenes with elemol being the main product. Because the sesquiterpenes $\beta$-elemene (PtTPS11) and elemol (PtTPS7) are known to arise as thermal rearrangement products from germacrene A [25] and hedycaryol [26], respectively, during hot GC injection, the products of PtTPS7 and PtTPS11 were also analyzed using a colder $\mathrm{GC}$ injector (temperature, $150^{\circ} \mathrm{C}$ ). Although $\beta$-elemene and elemol were still present in the GC chromatograms, an expansion of the germacrene A peak (PtTPS11) and hedycaryol peak (PtTPS7) could be observed, demonstrating the genuine activity of these enzymes (Additional file 1: Figure S6). In contrast to PtTPS5, PtTPS7, PtTPS9 and PtTPS11, the putative STS PtTPS14 showed only marginal activity with FPP and produced trace amounts of germacrene D (data not shown). PtTPS8, however, produced no sesquiterpenes. When offered GPP as a substrate, PtTPS11 formed several monoterpenes including myrcene, limonene, terpinolene and linalool (Figure 2B). Concerning the other STS, either trace activity (PtTPS5, PtTPS7, and PtTPS9) or no activity (PtTPS8, PtTPS14) was observed with GPP (data not shown). As predicted, PtTPS10 represented a DTS and was able to convert GGPP into geranyllinalool. Neither GPP nor FPP was accepted by PtTPS10. None of the other TPSs was able to accept GGPP as substrate.

A chiral analysis demonstrated that PtTPS9 formed exclusively the (-)-enantiomer of $(E)-\beta$-caryophyllene (Additional file 1: Figure S7A). For PtTPS15, the sesquiterpene product was (3S)-nerolidol while the monoterpene product was (3S)-linalool (Additional file 1: Figure $\mathrm{S} 7 \mathrm{~B}, \mathrm{~S} 7 \mathrm{C})$. A racemic mixture of $(3 S, 3 R)$-linalool was made by PtTPS12 (Additional file 1: Figure S7D). PtTPS11 formed (-)- $\beta$-elemene (Additional file 1: Figure S7E) which corresponds to (+)-germacrene $\mathrm{A}$ as the actual enzyme product because the stereochemical configuration is retained at $\mathrm{C} 7$ [25].

\section{TPS gene expression is affected by herbivory}

To analyze whether the expression of PtTPS5-15 is influenced by herbivory, the transcript abundance of these genes was measured using qRT-PCR in apical, herbivore-damaged leaves (LPI3, for a detailed description of leaf plastochron index (LPI) see material and 


\section{A sesquiterpene products}

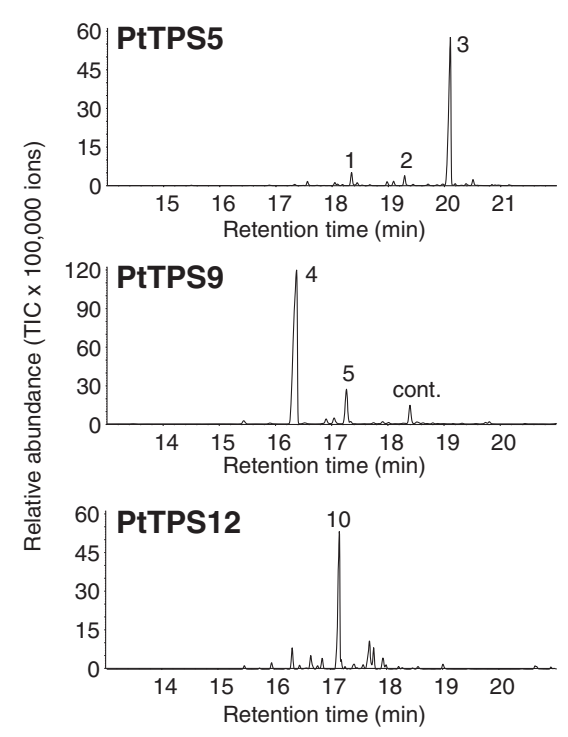

B monoterpene/diterpene products

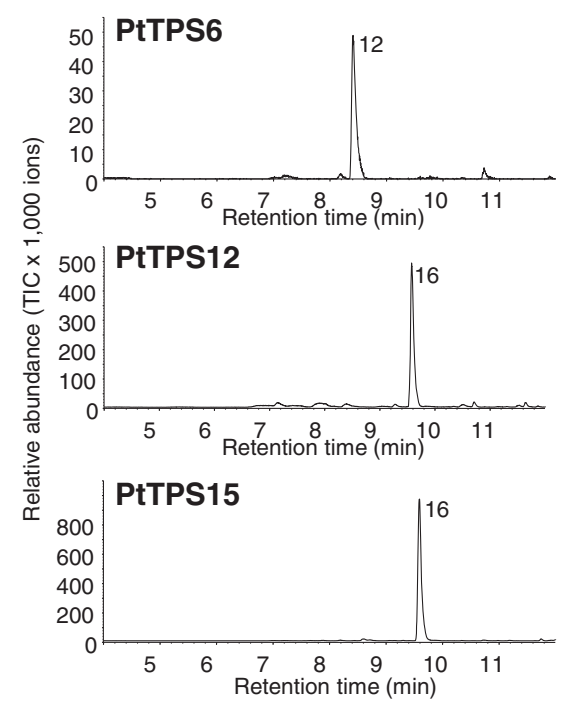

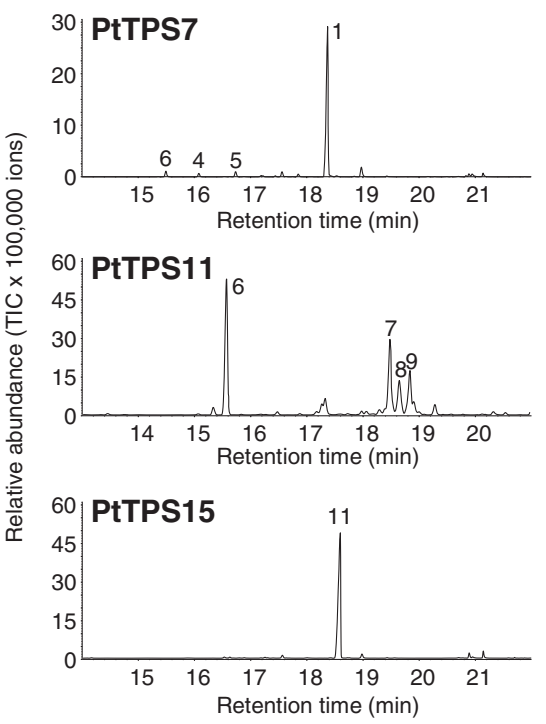

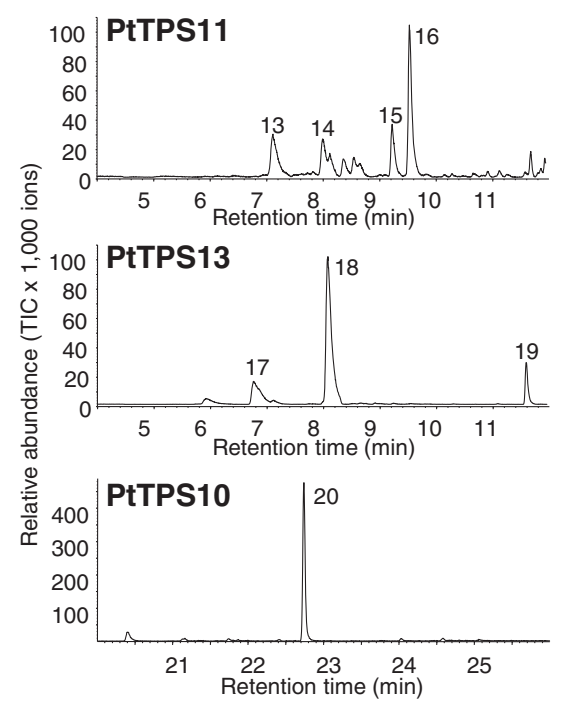

Figure 2 GC-MS analysis of sesquiterpenes (A), monoterpenes and diterpenes (B) produced by recombinant PtTPS5, PtTPS6, PtTPS7, PtTPS9, PtTPS10, PtTPS11, PtTPS12, PtTPS13 and PtTPS15. The enzymes were expressed in E. coli, extracted, partially purified, and incubated with the substrates FPP, GPP and GGPP. Products were collected with a solid-phase microextraction (SPME) fiber and analyzed by GC-MS. 1, elemol; 2, $\beta$-eudesmol*; 3, unidentified sesquiterpene alcohol; 4, (E)- $\beta$-caryophyllene*; 5, a-humulene*; 6, $\beta$-elemene*; 7, eremophilene; 8, a-selinene*; 9, unidentified sesquiterpene; 10, -curcumene*; $^{*}$ 11, nerolidol*; 12, (E)- $\beta$-ocimene*; 13, myrcene*; 14, limonene*; 15, terpinolene*; 16, linalool*; 17, sabinene*; 18, 1,8-cineole*; 19, terpineol*; 20, geranyllinalool*; cont., contamination. Compounds marked with * were identified using authentic standards.

methods) compared to the respective undamaged leaves from control trees. The expression levels of PtTPS5-15 generally increased after herbivore attack (Figure 3). Six of these genes were slightly upregulated, about 2- to 8fold, with the increases in transcript accumulation significant for PtTPS9, PtTPS10, PtTPS12 and PtTPS15 but not for PtTPS5 and PtTPS11/14 (Figure 3, Additional file 2: Table S2). Repeated sequencing of amplicons from
PtTPS11/14-qRT-PCR reactions revealed a 1:4 ratio of PtTPS11 to PtTPS14 transcript. A larger significant induction could be shown for PtTPS7 and PtTPS13, with 24.1-fold and 13.3-fold higher transcript abundance, respectively, in the damaged leaf compared to the undamaged control leaf (Figure 3). PtTPS6 showed the strongest response to herbivore damage with a 44.1-fold increase in transcript abundance (Figure 3, Additional file 2: 

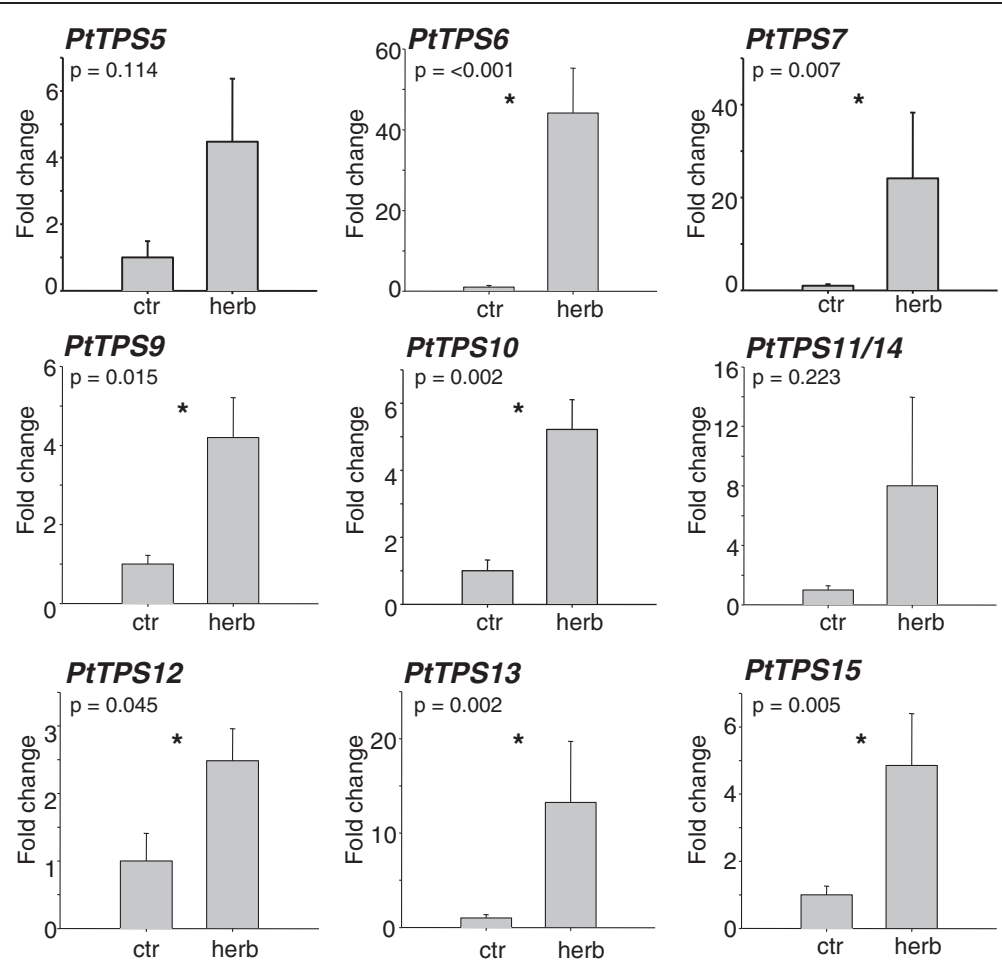

Figure 3 Transcript abundance of terpene synthase genes in herbivore-damaged (herb) and undamaged control (ctr) leaves of P. trichocarpa. Caterpillars were allowed to feed for $24 \mathrm{~h}$ on apical LPI3 (leaf plastochron index 3) leaves. Gene expression was determined by qRT-PCR. Means and standard errors are shown $(n=5)$. The student's t-test was used to test for statistical significance. Asterisks indicate a significant difference between herbivore-infested and untreated control leaves. ctr, control treatment; herb, herbivory.

Table S2). No qRT-PCR analysis was performed for PtTPS8 as no activity could be observed for the corresponding protein. Altogether the qRT-analysis showed distinct differences in the $\Delta C q$ values $\left(C q_{T P S}-C q_{\text {house-keeping gene }}\right)$ for the identified PtTPS genes (Additional file 2: Table S3). PtTPS11/14 and PtTPS12 had $\Delta C q$-values higher than 15 indicating low expression levels. In contrast, small $\Delta C q$ values were observed for PtTPS6 and PtTPS9 indicating higher transcript abundance compared to the other PtTPS genes.

\section{Leaf age and position influence the quantitative} composition of the herbivore-induced volatile blend

Our previous studies [10,21] already documented the complex volatile bouquet released from entire P. trichocarpa trees after damage by gypsy moth. To address the question of whether terpene emission is influenced by leaf age and position, we carried out a volatile collection from individual leaves (Additional file 1: Figure S8). A WAX (polyethyleneglycol) column with a length of $60 \mathrm{~m}$ was used for GC-MS analysis to ensure a better separation of the complex volatile mixtures. Single herbivoredamaged leaves emitted up to 78 different volatiles of which 58 could be identified (Additional file 2: Table S4).
As previously described, $(E)$ - $\beta$-ocimene, a monoterpene, and $(E, E)$ - $\alpha$-farnesene, a sesquiterpene likely produced by the sesquiterpene synthase PtTPS2, were the most abundant volatiles (Figure 4) [21]. Furthermore, the emission of (Z)-3-hexenol, 2-phenylethanol, benzaldehyde, benzyl cyanide and indole were also highly induced after herbivore feeding (Additional file 2: Table S4). In contrast to damaged leaves, neighboring non-infested leaves emitted only minor amounts of volatiles comparable to leaves from non-infested control trees, indicating that no systemic induction took place.

A comparison of the volatile blends released from uninfested leaves of different age stages (LPI3 to LPI10) revealed quantitative differences for single compounds within the tree (Additional file 2: Table S4). In undamaged control trees, linalool $\left(\mathrm{p}=0.008, \mathrm{R}^{2}=0.18\right)$ and $(E)$ $\beta$-ocimene $\left(p=0.036, R^{2}=0.12\right)$ were mainly emitted from younger apical leaves whereas $(Z)-3$-hexenol $(\mathrm{p}=0.05$, $\left.R^{2}=0.1\right)$, nonanal $\left(p=0.007, R^{2}=0.18\right)$ and nonanol $\left(p=0.09, R^{2}=0.12\right)$ were more dominant in the volatile blends emitted from older basal leaves. However, $(E)$ - $\beta$-caryophyllene $(\mathrm{p}=0.87)$ and $(E, E)$ - $\alpha$-farnesene $(\mathrm{p}=0.76)$ were emitted in similar amounts independent of leaf position (Figure 4, Additional file 2: Table S4). After 


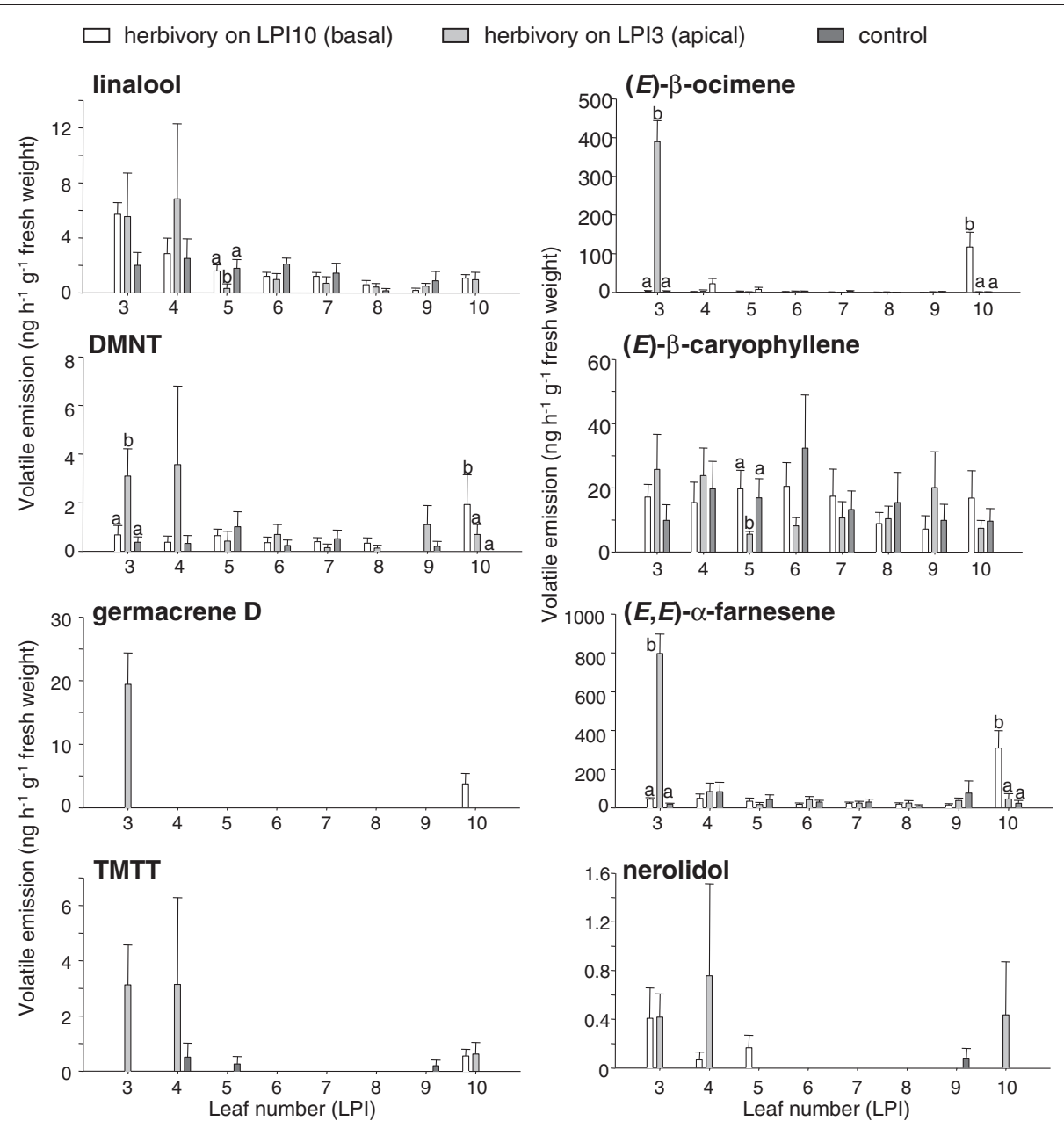

Figure 4 Terpene emission from individual $P$. trichocarpa leaves after herbivory restricted to an apical or basal leaf or no herbivory. Volatiles of eight single leaves, leaf plastochron indices 3 to 10 (LPI3 to LPI10) were measured from either control trees (ctr), trees which received herbivory apically on leaf LPI3 (ha, herbivory apical) or basally on leaf LPI10 (hb, herbivory basal). After separation by GC, the peaks were identified by MS and quantified using an FID. Means and standard errors are shown $(n=5)$. To test for statistical significance between the treatments in one leaf position, a one way analysis of variance (ANOVA) was performed. Different letters show significant differences. Germacrene D, TMTT and nerolidol were not tested for significance. $L$ ratios and $p$ values are given in Additional file 2: Table S6.

herbivore infestation of a younger apical leaf (LPI3) or an older basal leaf (LPI10), this developmental difference became even clearer. Younger damaged leaves near the apex generally emitted more terpenes (apical $1297 \pm$ $143 \mathrm{ng} \mathrm{h}^{-1} \mathrm{~g}^{-1}$ fresh weight vs. basal $475 \pm 96 ; \mathrm{p}=$ $0.001 ; \mathrm{t}=-4.768$; Figure 4, Additional file 2: Table S5), benzaldehyde $(p=0.008, T=15)$ and the ester phenylethyl acetate $(\mathrm{p}=0.003, \mathrm{t}=-4.165)$ compared to older damaged leaves near the base (Additional file 2: Table S4). However, the alcohol nonanol was found to be released in higher quantities from older damaged leaves $(p=0.041$, $t=2.437$ ). Nitrogen-containing compounds displayed a similar induction pattern independent of the leaf age, except for phenylnitroethane $(\mathrm{p}=0.008, \mathrm{~T}=15)$ and indole $(\mathrm{p}=0.004, \mathrm{t}=-3.927)$, which were more abundant in younger damaged leaves, (Additional file 2: Table S4).
The local and systemic emission of (E)- $\beta$-ocimene and (E)- $\beta$-caryophyllene can be correlated to the expression patterns of PtTPS6 and PtTPS9, respectively

To determine whether local and systemic terpene emission pattern are reflected by TPS gene expression, the transcript abundance of the $(E)-\beta$-ocimene synthase PtTPS6 and the (E)- $\beta$-caryophyllene synthase PtTPS9 were measured in gypsy moth-damaged leaves (LPI3 and LPI10), the closest neighboring leaves (LPI4 and LPI9, respectively) and the leaves to which they are most closely vascularly connected (LPI8 and LPI5, respectively) [27,28]. PtTPS6 gene expression was significantly increased in both herbivore-damaged LPI3 and LPI10 leaves. However, the induction was greater in the younger apical LPI3 leaf than in the older basal LPI10 leaf (Figure 5, Additional file 2: Table S2, S6). In contrast, PtTPS9 was slightly induced in the apical LPI3 leaf 
and not induced in the basal LPI10 leaf (Figure 5, Additional file 2: Table S2, S6). Altogether, transcript abundance of PtTPS6 was strongly upregulated in herbivore-damaged leaves in comparison to the most adjacent leaves and vascularly connected leaves of the damaged tree as well as in comparison to all leaves measured on undamaged control trees. On the other hand, PtTPS9 gene expression was hardly influenced by herbivory. No significant upregulation of PtTPS9 transcripts in neighboring leaves or vascularly connected leaves could be detected (Figure 5, Additional file 2: Table S2, S6).

\section{The concentrations of jasmonates increased in herbivore-damaged leaves}

As herbivore-induced volatile emission is commonly mediated by jasmonates and other phytohormones [29-31], we measured the concentrations of these compounds in individual leaves (LPI 3-10) of trees which suffered herbivory either on an apical leaf (LPI 3) or a basal leaf (LPI10). As illustrated in Figure 6, undamaged control trees showed a gradient for abscisic acid $\left(A B A ; R^{2}=0.23\right.$, $\mathrm{p}=0.001)$ and salicylic acid $\left(\mathrm{SA} ; \mathrm{R}^{2}=0.4, \mathrm{p}=0.009\right)$ within the tree with higher concentrations in younger leaves.
Conversely, 12-oxo-phytodienoic acid (OPDA) concentrations increased in older basal leaves $\left(\mathrm{R}^{2}=0.55, \mathrm{p}=<0.0001\right)$ while jasmonic acid (JA) and its isoleucine conjugates (JA-Ile), (-)-jasmonoyl-L-isoleucine and (+)-7-iso-jasmonoylL-isoleucine, were equally distributed throughout the tree $(\mathrm{p}=0.44 ; \mathrm{p}=0.76 ; \mathrm{p}=0.94$, respectively). Upon herbivore damage, the concentrations of JA and JA-Ile conjugates increased significantly and specifically in the damaged leaves independent of leaf position compared to undamaged leaves of control trees and leaves within the same tree (Figure 6, Additional file 2: Table S6). A significant induction of SA, ABA and OPDA occurred only after apical damage in damaged leaves or below (Figure 6, Additional file 2: Table S6).

\section{Discussion}

The TPS- $a$ and TPS- $b$ subfamilies in poplar are large and consist of members arisen by duplication events

Land plants generally possess a mid-size TPS gene family resulting from repeated gene duplication [12]. In this study we documented that the genome of $P$. trichocarpa contains 38 full length TPS genes in its current annotation (Figure 1). Hence, the poplar TPS gene family is comparable in size with the TPS gene families in 

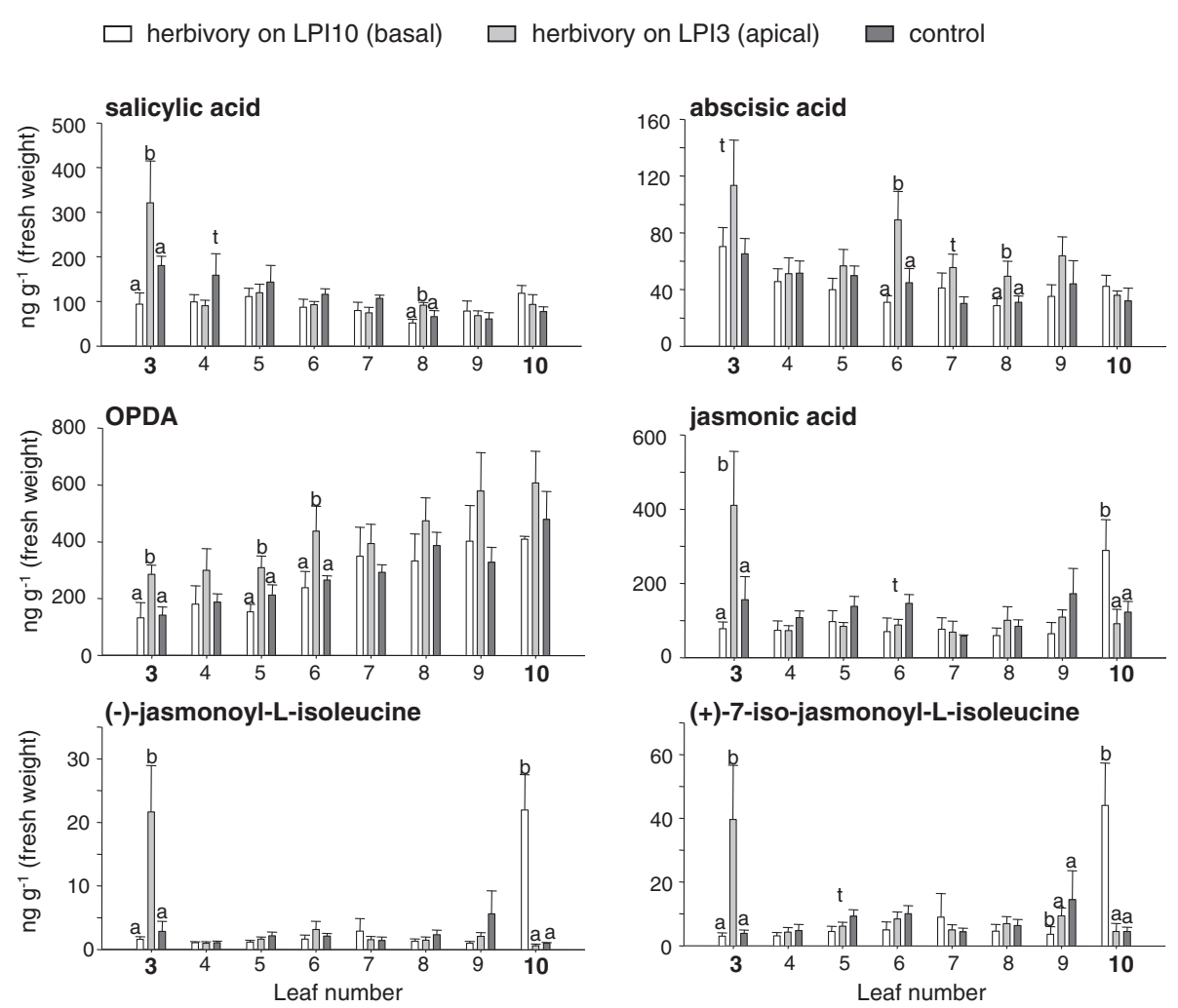

Figure 6 Phytohormone concentrations in individual P. trichocarpa leaves after herbivory restricted to an apical or basal leaf or no herbivory. Single leaves were measured from either control trees (ctr), trees which received herbivory apically on leaf LPI3 (ha, herbivory apical) or basally on leaf LPI10 ( $h b$, herbivory basal). Means and standard errors are shown $(n=5)$. To test for statistical significance between the treatments in one leaf position, a one way analysis of variance (ANOVA) was performed. Different letters show significant differences. $t$ indicates a trend $(0.05<p<0.1)$.

Arabidopsis (32 TPS genes) [32], rice (Oryza sativa, 34 TPS genes) [33], sorghum (Sorghum bicolor, 24 TPS genes) [34] and tomato (29 TPS genes) [35]. In contrast, the genomes of grape (Vitis vinifera), white spruce (Picea glauca) and S. moellendorfii contain larger TPS gene families with 69, 69 and 66 putative functional TPS genes, respectively [12]. The TPS gene family in apple, however, is made up of only 10 putative functional TPS genes [36]. The majority of the poplar TPSs was found to cluster within the TPS- $a$ and TPS- $b$ subfamilies (Additional file 1: Figure S1). These clades generally contain TPS involved in sesquiterpene formation or in monoterpene formation, respectively [13]. In Arabidopsis multiple gene duplication events occurred within the TPS- $a / b$ gene subfamilies [32]. The existence of multiple copies of TPS- $a / b$ genes in poplar suggests a similar mechanism of gene duplication in this species. The high number of TPS- $a / b$ genes stands in contrast to the two genes found in each of the poplar TPS-c and TPS-e subfamilies. These subfamilies commonly contain copalyl diphosphate synthases (CDS) and kaurene/kaurene-like synthases (KS/KSL), respectively, which can be involved in plant secondary as well as primary metabolism. Smaller TPS-c and TPS-e subfamilies were also described for conifer [37] and grape
[38] and Arabidopsis contains only a single CDS and a single KS gene [32].

\section{PtTPS6, 9, 10, 12 and 15 may contribute to herbivore-induced volatile formation}

The monoterpene synthase PtTPS6 was shown to produce $(E)$ - $\beta$-ocimene, one of the most abundant compounds in the herbivore-induced volatile blend of poplar. Upon herbivory, a significant increase in PtTPS6 transcript accumulation could be observed, suggesting a role of PtTPS6 in herbivore-induced $(E)$ - $\beta$-ocimene formation in planta (Figures 4,5 ). (E)- $\beta$-ocimene can be produced by a large number of plant species in floral scent [39], as a herbivore-induced volatile of leaves, e.g. tobacco (Nicotiana spp), corn (Zea mays), cotton (Gossypium hirsutum) and Arabidopsis plants [5,9,40,41], and also as part of essential oils, e.g. chamomile (Matricaria recutita) [42]. When added to the spider mite-induced volatile blend of wishbone flower (Torenia hybrida), $(E)$ - $\beta$-ocimene was able to enhance the blend's ability to attract predatory mites [43]. In contrast, a repellent effect of $(E)$ - $\beta$-ocimene was observed for another herbivore enemy, Glyptapanteles liparidis, a parasitoid of the gypsy moth larvae [7]. Besides its effect on insects, 
(E)- $\beta$-ocimene can also function in plant-plant communication by mediating the induction of defense related genes $[44,45]$. Thus the $(E)$ - $\beta$-ocimene synthase PtTPS6 might play different roles in direct or indirect defense of poplar.

Linalool, another prominent constituent of the poplar volatile bouquet, can be produced by PtTPS3 and PtTPS12 [21] (Figure 2). While PtTPS3 formed exclusively (+)-(3S)linalool, PtTPS12 produced a racemic linalool mixture (Additional file 1: Figure S7). As poplar emits (+)-(3S)-linalool as well as $(-)-(3 R)$-linalool [21], both enzymes may contribute to linalool formation in the tree. The upregulation of PtTPS12 transcripts additionally supports the function of PtTPS12 in herbivore-induced volatile biosynthesis (Figure 3). Interestingly, PtTPS12 possessed also sesquiterpene synthase activity in vitro and formed a complex mixture of sesquiterpenes (Figure 2). However, a transit peptide at the N-terminus of PtTPS12 suggests a plastidal localization and thus an in vivo function as monoterpene synthase in accordance with the absence of PtTPS12 sesquiterpene products in the poplar volatile blend.

PtTPS15 was shown to encode a nerolidol synthase (Figure 2). This TPS clusters within the TPS-g family together with PtTPS3 (Additional file 1: Figure S4) [21]. Both terpene synthases are characterized by the absence of the $R R(x)_{8} W$-motif, which is a typical feature of members of the TPS-g clade [35]. PtTPS15 and PtTPS3 produce $(+)-(3 S)$-nerolidol in vitro, the enantiomer also present in the poplar scent (Additional file 1: Figure S7) [21]. In contrast to PtTPS3, PtTPS15 does not have a transit peptide and is therefore more likely responsible for (+)-(3S)-nerolidol biosynthesis in planta. Nerolidol has been shown to be converted into the homoterpene DMNT which is considered to play an important role in plant defense [12]. Danner and coworkers (2011) already speculated about the involvement of the (-)-(3R)-nerolidolproducing PtTPS4 in herbivore-induced DMNT biosynthesis. As the expression of PtTPS4 was only slightly induced after herbivore attack, the existence of another nerolidol synthase was predicted. Since transcript accumulation of PtTPS15 was strongly upregulated after herbivore damage, it is likely that PtTPS15 contributes to the production of the precursor for DMNT biosynthesis in planta (Figure 3). TMTT is another homoterpene emitted by $P$. trichocarpa. The precursor of TMTT, geranyllinalool, was produced by the diterpene synthase PtTPS10 (Figure 2). The transcript level of PtTPS10 increased after herbivore damage which corresponded to the induced emission of TMTT (Figure 3). Both DMNT and TMTT are described to be emitted from several plants including maize, lima bean, Arabidopsis and tomato [46,47] and a role of TMTT and DMNT in, for example, predatory mite attraction in tomato and Arabidopsis, respectively, has been demonstrated $[48,49]$.

The volatile $(E)$ - $\beta$-caryophyllene has been reported to attract enemies of both above- and below-ground maize herbivores [50]. In our study, $(E)$ - $\beta$-caryophyllene emission was not significantly increased after herbivore damage but showed a trend to higher emission from damaged leaves corresponding to a small increase in $(E)$ - $\beta$-caryophyllene synthase (PtTPS9) transcripts (Figures 4, 5). However, Danner and coworkers (2011) described $(E)-\beta$ caryophyllene as an herbivore-inducible poplar volatile. Plant age, greenhouse conditions and previous infections could have led to already increased levels of $(E)$ - $\beta$-caryophyllene in plants used for the present study.

1,8-Cineole, the main product of PtTPS13, was only present in trace amounts in the herbivore-induced volatile blend of $P$. trichocarpa (Figure 2, Additional file 2: Table S4). A low transcript abundance (indicated by a high $\Delta C q$-value, Additional file 2: Table S3) is likely to be the reason for this low emission (Figure 3). The in vitro products of PtTPS5, PtTPS7 and PtTPS11 (sesquiterpene alcohols and germacrene A, Figure 2) could not be detected in the herbivore-induced poplar volatile blend, although qRT-PCR analysis revealed a transcriptional upregulation in herbivore-damaged leaves in comparison to undamaged control leaves (Figure 3). Low transcript abundance (as indicated for PtTPS11 by a high $\triangle C q$ value; Additional file 2: Table S3), but also high $K_{m}$ values for FPP or low turnover numbers or lifetimes for the respective proteins could explain the lack of the respective in vitro products of the enzymes in the poplar volatile blend. Or, the products could be further converted into non-volatile metabolites, such as sesquiterpene phytoalexins. There are reports of sesquiterpene synthases involved in phytoalexin biosynthesis [51-55]. In maize, for example, the existence of an herbivoreinducible $\beta$-macrocarpene synthase and the absence of this sesquiterpene in the volatile blend led to the discovery of $\beta$-macrocarpene-derived phytoalexins [50,55]. Germacrene A, the major in vitro product of PtTPS11, was shown to be the precursor for sesquiterpene lactones in various plants like chicory (Cichorium intybus) and pyrethrum (Tanacetum cinerariifolium) [56-58]. Hence, we propose that sesquiterpene alcohols produced by PtTPS5 and PtTPS7 and germacrene A produced by PtTPS11 are further metabolized in poplar.

Altogether, out of the 38 putative TPS encoded in the poplar genome, 11 TPS enzymes could be functionally characterized in this study. Including the 4 previously published mono- and sesquiterpene synthases, the germacrene D synthase PtTPS1, the $(E, E)$ - $\alpha$-farnesene synthase PtTPS2, and the linalool/nerolidol synthases PtTPS3 and PtTPS4 [21] as well as the isoprene synthase [22], about half of the TPS genes present in the genome have now 
been characterized and their enzymatic function in vitro determined. Nearly all of the terpenes emitted by poplar after herbivory can be explained by the enzyme activities of the 15 so far characterized mono-, sesqui- and diterpene synthases (Additional file 2: Table S8). Nevertheless it is possible that additional TPS genes are expressed in other organs of $P$. trichocarpa as it was already described for other plants. For example, TPS genes specifically expressed in flowers or roots were described for chamomile and Arabidopsis [42,59,60].

\section{Herbivore-induced terpene emission in P. trichocarpa is restricted to the damaged leaf and likely mediated by jasmonates}

A comparison of the qualitative and quantitative composition of the volatile blends released locally from herbivore-damaged leaves and systemically from undamaged adjacent leaves has been described for $P$. nigra and hybrid poplar ( $P$. trichocarpa $\mathrm{x}$ deltoides) $[7,20]$. In both studies, a systemic volatile induction in the undamaged leaves above the site of herbivore-damage was reported. On the contrary, we showed that no systemic induction of volatiles was occurring at the level of an individual leaf in P. trichocarpa (Additional file 2: Table S4, S5). As already observed in maize [61], volatile emission was restricted to the damaged leaf. This specific local volatile emission could be important in intra-plant signaling and provides a reliable short-range signal for parasitoids searching for their hosts.

Jasmonic acid and their amino acid conjugates are well known as mediators of herbivore-induced plant defenses, including the emission of volatiles in many plant species $[31,62]$. In a recent publication, Clavijo McCormick and coworkers (2014) demonstrated that jasmonates were upregulated after herbivory in black poplar. Moreover, exogenous application of JA to $P$. nigra and $P$. trichocarpa leaves resulted in increased volatile emission [7] (Additional file 2: Table S9) and a transcriptome analysis of $P$. trichocarpa $\mathrm{x}$ deltoides leaves treated with forest tent caterpillars (Malocosoma disstria) revealed an upregulation of genes involved in both jasmonate biosynthesis as well as volatile formation [63]. The herbivoreinduced local terpene emission of $P$. trichocarpa was also reflected by increased levels of TPS transcripts and jasmonates in the damaged leaves in comparison to undamaged adjacent leaves (Figures 5, 6). Therefore JA and JA-Ile conjugates appear to be major signals for transcriptional regulation of volatile biosynthesis in P. trichocarpa.

Although volatile emission of black poplar is inducible by JA application but not by SA application, SA levels are increased after herbivore feeding [7]. In our experiments with $P$. trichocarpa, only herbivory on younger apical leaves resulted in significantly increased SA concentrations in damaged leaves (Figure 6). Interestingly, elevated levels of SA were also detected in the vascularconnected leaf (LPI of the herbivore-damaged leaf +5 ) $[27,28]$ beneath the herbivore-damaged leaf (Figure 6). Additionally, apical herbivory resulted in increased concentrations of OPDA and ABA in basal leaves (Figure 6). A mobile signal travelling from the apical leaves downward could explain these observations and would provide a reasonable mechanism for the basipetal, systemic defense reactions already described for poplar [64].

\section{Conclusions}

In this study we investigated the terpene synthase gene family in $P$. trichocarpa and its contribution to herbivoreinduced volatile formation. The production of volatile terpenes in poplar is mainly regulated by transcript accumulation of multiple TPS genes. The restriction of volatile release to the damaged leaf might play a role in intra-plant signaling and help herbivore enemies to better find their hosts or preys in the tree canopy. While about one third of all poplar TPSs seem to be involved in herbivoreinduced volatile terpene production, the function of other TPS is still unclear. They might play roles in other defense reactions in the different organs of poplar trees.

\section{Methods}

\section{Plant and insect material}

Western balsam poplar (Populus trichocarpa) trees were propagated from monoclonal stem cuttings (clone 625, NW-FVA, Hann. Münden, Germany) and grown under summer conditions in the greenhouse $\left(24^{\circ} \mathrm{C}, 60 \%\right.$ rel. humidity, $16 \mathrm{~h} / 8 \mathrm{~h}$ light/dark cycle) in a 1:1 mixture of sand and soil (Klasmann potting substrate), until they reached about $1 \mathrm{~m}$ in height. Gypsy moth (Lymantria dispar) egg batches were kindly provided by Hannah Nadel, APHIS, USA. After hatching, the caterpillars were reared on an artificial diet (Gypsy moth diet, MP Biomedicals LLC, Illkirch, France).

\section{Poplar volatile collection and analysis}

To investigate the spatial distribution of volatile emission after gypsy moth feeding, we conducted single-leaf volatile collections. Eight leaves (from LPI3 to LPI10, LPI = leaf plastochron index [28]) from each tree were individually enclosed with a PET bag ("Bratschlauch", Toppits, Minden, Germany) by fixing the ends with cable binders. Trees were infested with $L$. dispar larvae on either an apical leaf (LPI3) or a basal leaf (LPI10) and volatiles were separately collected from leaves LPI3 to LPI10 (Additional file 1: Figure S8). Five L. dispar caterpillars in third to fourth instar starved for $12 \mathrm{~h}$ were released on the leaves. The caterpillars were fed with poplar leaves for one week prior to the onset of the experiment. Caterpillars were allowed to feed for $24 \mathrm{~h}$ (16.00 (day 1) - $16.00 \mathrm{~h}$ (day 2)). Volatiles were collected 
for 6 hours during the middle of the light period of day $2(10.00-16.00 \mathrm{~h})$ after caterpillar removal using a push-pull system as described by Tholl et al. (2006) [65]. Air flow was maintained in the system through teflon tubes. Charcoal-filtered air was constantly pumped into the bags at a flow rate of $1.5 \mathrm{l} / \mathrm{min}$. The outgoing air (flow: $1 \mathrm{l} / \mathrm{min}$ ) passed a filter packed with $30 \mathrm{mg}$ Super Q (ARS, Inc., Gainesville, FL, USA) to adsorb the volatile compounds. After collection the volatiles were desorbed by eluting the filter twice with $100 \mu \mathrm{L}$ dichloromethane containing nonyl acetate as an internal standard $\left(10 \mathrm{ng} \mu \mathrm{L}^{-1}\right)$. Five replicates each of LPI3-treated trees, LPI10-treated trees and undamaged control trees were measured.

Qualitative and quantitative volatile analysis was conducted using an Agilent 6890 Series gas chromatograph coupled to an Agilent 5973 quadrupole mass selective detector (interface temp, $250^{\circ} \mathrm{C}$; quadrupole temp, $150^{\circ} \mathrm{C}$; source temp, $230^{\circ} \mathrm{C}$; electron energy, $70 \mathrm{eV}$ ) or a flame ionization detector (FID) operated at $300^{\circ} \mathrm{C}$, respectively. The constituents of the volatile bouquet were separated using a ZB-WAX column (Phenomenex, Aschaffenburg, Germany, $60 \mathrm{~m} \times 0.25 \mathrm{~mm} \times 0.15 \mu \mathrm{m})$ and He (MS) or $\mathrm{H}_{2}$ (FID) as carrier gas. The sample $(1 \mu \mathrm{L})$ was injected without split at an initial oven temperature of $40^{\circ} \mathrm{C}$. The temperature was held for $2 \mathrm{~min}$ and then increased to $225^{\circ} \mathrm{C}$ with a gradient of $5^{\circ} \mathrm{C} \mathrm{min}^{-1}$, held for another $2 \mathrm{~min}$ and then further increased to $250^{\circ} \mathrm{C}$ with a gradient of $100^{\circ} \mathrm{C} \mathrm{min} \mathrm{min}^{-1}$ and a hold of $1 \mathrm{~min}$. Compounds were identified by comparison of retention times and mass spectra to those of authentic standards obtained from Fluka (Seelze, Germany), Roth (Karlsruhe, Germany), Sigma (St. Louis, MO, USA), Bedoukian (Danbury, CT, USA), or by reference spectra in the Wiley and National Institute of Standards and Technology libraries. Aldoxime standards were synthesized as described in Irmisch et al. 2013 [10].

\section{Plant tissue sampling, RNA extraction and reverse transcription}

Poplar material was harvested after $24 \mathrm{~h}$ of herbivory, flash-frozen with liquid nitrogen and stored at $-80^{\circ} \mathrm{C}$ until further processing. After grinding, the total RNA was isolated using an Invisorb Spin Plant RNA Mini Kit (Invitek $\mathrm{GmbH}$, Berlin, Germany) according to the manufacturer's instructions. RNA concentration, purity and quality were accessed using a spectrophotometer (NanoDrop 2000c, Thermo Scientific, Wilmington, USA) and an Agilent 2100 Bioanalyzer (Agilent Technologies $\mathrm{GmbH}$, Waldbronn, Germany). Prior to cDNA synthesis, $0.75 \mu \mathrm{g}$ RNA was DNase-treated using $1 \mu \mathrm{L}$ DNase (Fermentas $\mathrm{GmbH}$, St. Leon Roth, Germany). Single-stranded cDNA was prepared from the DNase-treated RNA using SuperScript ${ }^{\mathrm{Tm}}$ III reverse transcriptase and oligo $\left(\mathrm{dT}_{12-18}\right)$ primers (Invitrogen, Carlsbad, CA, USA).

\section{Identification and isolation of PtTPS genes}

To identify putative poplar TPS genes, a BLAST search against the $P$. trichocarpa genome database (http://www.phytozome.net/poplar) using PtTPS1 (JF449450) and AtGAS2 (Q9SAK2) as inqury sequences was conducted. Thirtyeight full length TPS genes, having a minimum length of 520 amino acids were identified. Fifteen (including PtTPS1-4) [21] of these sequences could be amplified from cDNA obtained from herbivore-damaged leaves of P. trichocarpa. Primer sequence information is available in Additional file 2: Table S10. PCR products were cloned into the sequencing vector $\mathrm{pCR}^{\oplus-}$ Blunt II-TOPO ${ }^{\circ}$ (Invitrogen) and both strands were fully sequenced. Signal peptide prediction was done using the TargetP 1.1 server (http://www.cbs.dtu.dk/services/TargetP/) and a positive prediction was taken if the reliability class ( $\mathrm{RC}$-value) was greater than 4 . Sequences were deposited in GenBank with the accession numbers KF776503 (PtTPS5), KF776504 (PtTPS6), KF776505 (PtTPS7), KF776506 (PtTPS8), KF776507 (PtTPS9), KF776508 (PtTPS10), KF776509 (PtTPS11), KF776510 (PtTPS12), KF776511 (PtTPS13), KF776512 (PtTPS14), KF776502 (PtTPS15).

\section{Heterologous expression of PtTPS in E. coli}

The open reading frames of the TPS genes were cloned as $B s a \mathrm{I}$ fragments into the pASK-IBA7 vector (IBA-GmbH, Göttingen, Germany). The E. coli strain TOP10 (Invitrogen) was used for expression. Cultures were grown at $37^{\circ} \mathrm{C}$, induced at an $\mathrm{OD}_{600}=0.6$ with $200 \mathrm{ug} / \mathrm{l}$ anhydrotetracycline (IBA-GmbH) and subsequently placed at $18^{\circ} \mathrm{C}$ and grown for another 20 hours. The cells were collected by centrifugation and disrupted by a $3 \times 30 \mathrm{~s}$ treatment with a sonicator (Bandelin UW2070, Berlin, Germany) in chilled extraction buffer (50 mM Mopso, pH 7.0, with $5 \mathrm{mM}$ $\mathrm{MgCl}_{2}, 5 \mathrm{mM}$ sodium ascorbate, $0.5 \mathrm{mM}$ PMSF, $5 \mathrm{mM}$ dithiothreitol and $10 \%(\mathrm{v} / \mathrm{v})$ glycerol). Cell fragments were removed by centrifugation at $14,000 \mathrm{~g}$ and the supernatant was desalted into assay buffer (10 mM Mopso, $\mathrm{pH} 7.0$, $1 \mathrm{mM}$ dithiothreitol, $10 \%$ (v/v) glycerol) by passage through a Econopac 10DG column (BioRad, Hercules, CA, USA).

\section{Analysis of recombinant PtTPS}

To determine the catalytic activity of the different terpene synthases, enzyme assays containing $40 \mu \mathrm{l}$ of the bacterial extract and $60 \mu \mathrm{l}$ assay buffer with $10 \mu \mathrm{M}(E, E)$-FPP or (E)-GPP and $10 \mathrm{mM} \mathrm{MgCl}_{2}$, in a Teflon-sealed, screwcapped $1 \mathrm{ml} \mathrm{GC}$ glass vial were performed. A SPME (solid phase microextraction) fiber consisting of $100 \mu \mathrm{m}$ polydimethylsiloxane (SUPELCO, Belafonte, PA, USA) was placed into the headspace of the vial for $45 \mathrm{~min}$ incubation at $30^{\circ} \mathrm{C}$. For analysis of the adsorbed reaction products, the SPME fiber was directly inserted into the injector of the gas chromatograph. To determine 
diterpene synthase activity, assays were set up as described above, containing $50 \mu \mathrm{M}(E, E, E)$-GGPP as substrate, and overlaid with $100 \mu \mathrm{l}$ hexane. After incubation for $60 \mathrm{~min}$ at $30^{\circ} \mathrm{C}$ the hexane phase was collected and analyzed using GC-MS.

As a negative control, we incubated raw protein extracts from $E$. coli expressing the empty vector pASKIBA7 with the substrates GPP, FPP, and GGPP, respectively, as described above. As shown in Additional file 1: Figure S9, no terpene hydrocarbon or terpene alcohols were formed with the exception of a very few GPP and FPP hydrolysis products which were probably produced by unspecific $E$. coli phosphatases.

The TPS enzyme products were analyzed and identified using GC-MS as described above for poplar volatiles. The GC was operated with a DB-5MS column (Agilent, Santa Clara, USA, $30 \mathrm{~m} \times 0.25 \mathrm{~mm} \times 0.25 \mu \mathrm{m})$. The sample (SPME) was injected without split at an initial oven temperature of $50^{\circ} \mathrm{C}$. The temperature was held for $2 \mathrm{~min}$, then increased to $240^{\circ} \mathrm{C}$ with a gradient of $7^{\circ} \mathrm{C} \mathrm{min}{ }^{-1}$, and further increased to $300^{\circ} \mathrm{C}$ with a gradient of $60^{\circ} \mathrm{C} \mathrm{min}{ }^{-1}$ and a hold of $2 \mathrm{~min}$. For the GC-MS analysis with a cooler injector, the injector temperature was reduced from $220^{\circ} \mathrm{C}$ to $150^{\circ} \mathrm{C}$. For volatile diterpene analysis, $2 \mu \mathrm{l}$ of the hexane samples were injected without split at an initial oven temperature of $80^{\circ} \mathrm{C}$. The temperature was held for $2 \mathrm{~min}$, than increased to $250^{\circ} \mathrm{C}$ with a gradient of $7^{\circ} \mathrm{C} \mathrm{min}{ }^{-1}$, and further increased to $320^{\circ} \mathrm{C}$ with a gradient of $100^{\circ} \mathrm{C} \mathrm{min}$ and a hold of $2 \mathrm{~min}$.

Chiral GC-MS analysis was performed using a $\mathrm{Rt}^{\mathrm{TM}}$ $\beta$ DEXsm-column (Restek, Bad Homburg, Germany) and a temperature program from $50^{\circ} \mathrm{C}(2 \mathrm{~min}$ hold $)$ at $2^{\circ} \mathrm{C} \mathrm{min}^{-1}$ to $220^{\circ} \mathrm{C}$ ( $1 \mathrm{~min}$ hold). Enantiomers were identified using authentic standards obtained from (Fluka, Seelze, Germany). A racemic mixture of $(E)$ - $\beta$-caryophyllene was kindly provided by Stefan Garms (MPI for Chemical Ecology, Jena, Germany). A (+)-germacrene A synthase from chamomile MrTPS3 (Matricaria recutita) [42] was used to prepare an authentic (+)-germacrene A standard.

\section{qRT-PCR analysis of PtTPS expression}

RNA was isolated from leaves treated for $24 \mathrm{~h}$ with herbivory and cDNA was prepared as described above and diluted 1:3 with water. For the amplification of TPS gene fragments with a length between $110-200 \mathrm{bp}$, a gene specific primer pair was designed having a $\mathrm{T}_{\mathrm{m}}$ of about $60^{\circ} \mathrm{C}$, a GC content between $40-55 \%$ and a primer length in the range of 19-25 nt (Additional file 2: Table S9). Due to the high sequence similarity, only one primer pair was used for the amplification of PtTPS11 and PtTPS14. Sequencing of PCR products obtained from four biological replicates revealed the average percentage for the transcripts of PtTPS11 and PtTPS14.
Primer specificity was confirmed by agarose gel electrophoresis, melting curve analysis and standard curve analysis and by sequence verification of cloned PCR amplicons. Ubiquitin was used as a reference gene [66]. Samples were run in triplicates using Brilliant ${ }^{\oplus}$ III SYBR ${ }^{\odot}$ Green QPCR Master Mix (Stratagene, CA, USA) with ROX as reference dye. The following PCR conditions were applied for all reactions: Initial incubation at $95^{\circ} \mathrm{C}$ for $3 \mathrm{~min}$ followed by 40 cycles of amplification $\left(95^{\circ} \mathrm{C}\right.$ for $20 \mathrm{sec}, 60^{\circ} \mathrm{C}$ for $20 \mathrm{sec}$ ). Plate reads were taken during the annealing and the extension step of each cycle. Data for the melting curves were recorded at the end of cycling from $55^{\circ} \mathrm{C}$ to $95^{\circ} \mathrm{C}$.

All samples were run on the same PCR machine (MxPro - Mx3000P, Stratagene, Agilent Technologies, USA) in an optical 96-well plate. Five biological replicates were analyzed as triplicates in the qRT-PCR for each of the three treatments. Data for the relative quantity to calibrator average $(\mathrm{dRn})$ were exported from the MXPro Software.

\section{Phylogenetic tree reconstruction}

For the estimation of a phylogenetic tree, we used the MUSCLE algorithm (gap open, -2.9; gap extend, 0; hydrophobicity multiplier, 1.5; clustering method, upgmb) implemented in MEGA5 [67] to compute an amino acid alignment of all full length poplar TPS enzymes. Based on the MUSCLE alignment, the tree was reconstructed with MEGA5 using a neighbor-joining algorithm (Poisson model). A bootstrap resampling analysis with 1000 replicates was performed to evaluate the tree topology. Following this procedure, a phylogenetic tree containing the characterized PtTPS enzymes and other representative TPS enzymes was constructed. An additional tree showing the phylogenetic relation of all full length PtTPS genes and representative TPS genes from other plants was constructed using a clustal W alignment (nucleotides treated as triplicates) to build up a neighbor-joining tree using MEGA 5 as described above.

An alignment of all characterized PtTPS enzymes and an alignment of the putative diterpene synthases of poplar with other characterized diterpene synthases were constructed and visualized using BioEdit (http://www. mbio.ncsu.edu/bioedit/bioedit.html) and the ClustalW algorithm.

\section{Quantification of Jasmonic acid, JA-lle conjugates, OPDA, ABA and Salicylic acid}

For phytohormone analysis, $110 \mathrm{mg}$ of finely ground leaf material was extracted with $1 \mathrm{ml}$ of methanol containing $60 \mathrm{ng}$ of 9,10- $\mathrm{D}_{2}-9,10$-dihydrojasmonic acid , $60 \mathrm{ng} \mathrm{D}_{4^{-}}$ salicylic acid (Sigma-Aldrich), $60 \mathrm{ng} \mathrm{D}_{6}$-abscisic acid (Santa Cruz Biotechnology, Santa Cruz, CA, USA), and $15 \mathrm{ng}$ of jasmonic acid- $\left[{ }^{13} \mathrm{C}_{6}\right]$ isoleucine conjugate as 
internal standards. Jasmonic acid- $\left[{ }^{13} \mathrm{C}_{6}\right]$ isoleucine conjugate was synthesized as described by Kramell et al. (1988) using $\left[{ }^{13} \mathrm{C}_{6}\right]$ Isoleucine (Sigma-Aldrich) [68].

Chromatography was performed on an Agilent 1200 HPLC system (Agilent Technologies). Separation was achieved on a Zorbax Eclipse XDB-C18 column $(50 \times$ $4.6 \mathrm{~mm}, 1.8 \mu \mathrm{m}$, Agilent). Formic acid (0.05\%) in water and acetonitrile were employed as mobile phases $\mathrm{A}$ and $\mathrm{B}$, respectively. The elution profile was: $0-0.5 \mathrm{~min}, 5 \% \mathrm{~B}$; 0.5 $9.5 \mathrm{~min}, 5-42 \% \mathrm{~B}$; $9.5-9.51 \mathrm{~min} 42-100 \% \mathrm{~B}$; $9.51-12 \mathrm{~min}$ $100 \% \mathrm{~B}$ and $12.1-15 \mathrm{~min} 5 \% \mathrm{~B}$. The mobile phase flow rate was $1.1 \mathrm{ml} / \mathrm{min}$. The column temperature was maintained at $25^{\circ} \mathrm{C}$. An API 3200 tandem mass spectrometer (Applied Biosystems) equipped with a Turbospray ion source was operated in negative ionization mode. The instrument parameters were optimized by infusion experiments with pure standards, where available. The ion spray voltage was maintained at $4500 \mathrm{eV}$. The turbo gas temperature was set at $700^{\circ} \mathrm{C}$. Nebulizing gas was set at $60 \mathrm{psi}$, curtain gas at $25 \mathrm{psi}$, heating gas at $60 \mathrm{psi}$ and collision gas at $7 \mathrm{psi}$. Multiple reaction monitoring (MRM) was used to monitor analyte parent ion $\rightarrow$ product ion: $\mathrm{m} / z 136.9 \rightarrow 93.0$ (collision energy (CE )-22 V; declustering potential (DP) -35 V) for salicylic acid; $m / z 140.9 \rightarrow 97.0(\mathrm{CE}-22 \mathrm{~V}$; DP $-35 \mathrm{~V}$ ) for $\mathrm{D}_{4}$-salicylic acid; $m / z \quad 209.1 \rightarrow 59.0 \quad(\mathrm{CE} \quad-24 \quad \mathrm{~V}$; DP $-35 \mathrm{~V}$ ) for jasmonic acid; $m / z 213.1 \rightarrow 56.0(\mathrm{CE}-24 \mathrm{~V}$; DP $-35 \mathrm{~V}$ ) for 9,10-D2-9,10-dihydrojasmonic acid; $\mathrm{m} / \mathrm{z}$ $263.0 \rightarrow 153.2$ (CE $-22 \mathrm{~V}$; DP $-35 \mathrm{~V}$ ) for abscisic acid; $\mathrm{m} / z$ $269.0 \rightarrow 159.2\left(\mathrm{CE}-22 \mathrm{~V}\right.$; DP $-35 \mathrm{~V}$ ) for $\mathrm{D}_{6}$-abscisic acid; $m / z 322.2 \rightarrow 130.1(\mathrm{CE}-30 \mathrm{~V}$; DP $-50 \mathrm{~V})$ for jasmonic acid-isoleucine conjugate; $m / z \quad 328.2 \rightarrow 136.1(\mathrm{CE}-30 \mathrm{~V}$; DP -50 V) for jasmonic acid- $\left[{ }^{13} \mathrm{C}_{6}\right]$-isoleucine conjugate. Both Q1 and Q3 quadrupoles were maintained at unit resolution. Analyst 1.5 software (Applied Biosystems) was used for data acquisition and processing. Linearity in ionization efficiencies was verified by analyzing dilution series of standard mixtures. Phytohormones were quantified relative to the signal of their corresponding internal standard. For quantification of 12-oxophytodienoic acid, cis-OPDA, 9,10- ${ }_{2}-9,10$-dihydrojasmonic acid was used as the internal standard applying an experimentally determined response factor of 2.24 .

\section{Statistical analysis}

Whenever necessary, the data were log transformed to meet statistical assumptions such as normality and homogeneity of variances. Throughout the manuscript data are presented as means $\pm \mathrm{SE}$. To compare $P$. trichocarpa volatile emission of herbivore-induced leaves and their respective control leaves, emission from apical vs. basal leaves, and expression of TPS in leaves from herbivoreinduced trees vs. undamaged controls, Student's t-tests were performed with SigmaPlot 11.0 for Windows (Systat Software Inc. 2008). A linear regression was performed using R2.15.2 (R Development Core Team, http://www.Rproject.org) to check for gradients of volatile emission on the trees. To compare phytohormone concentrations in single leaves of P. trichocarpa and PtTPS6 and PtTPS9 gene expression in different single leaves of one tree, mixed-effects models (nlme package) with leaf number as fixed effect and plant identity as random effect were used, followed by a maximum likelihood ratio test. The testing for significant differences in phytohormone content and terpene emission between the apical, basal and control treatment in one leaf position was done using a one way analysis of variance (ANOVA). Models were simplified by factor level reduction [69], and were done with R2.15.2.

\section{Availability of supporting data}

Phylogenetic data (trees and the data used to generate them) have been deposited in TreeBASE respository and are available under the URL http://purl.org/phylo/treebase/phylows/study/TB2:S16450.

\section{Additional files}

Additional file 1: This file contains 9 supplemental figures.

Additional file 2: This file contains 10 supplemental tables.

\section{Competing interests}

The authors declare that they have no competing interests.

\section{Authors' contributions}

SI, YJ and TGK carried out the experimental work. FC and JG participated in the design of the study and improved the manuscript. SI and TGK conceived of the study and drafted the manuscript. All authors read and approved the final manuscript.

\section{Acknowledgements}

We thank Claudia Wenderoth and Katrin Luck for excellent technical assistance, Michael Reichelt for his help with the phytohormone analysis, Grit Kunert for here help with the statistics and Tamara Krügel and all the MPI-CE gardeners for their help with rearing the poplar trees. This work was supported by the Max-Planck-Society.

\section{Author details}

${ }^{1}$ Max Planck Institute for Chemical Ecology, Hans-Knöll-Strasse 8, D-07745, Jena, Germany. '2Department of Plant Sciences, University of Tennessee, Knoxville, TN37996, USA.

Received: 12 June 2014 Accepted: 1 October 2014

Published online: 11 October 2014

\section{References}

1. Gershenzon J, Dudareva N: The function of terpene natural products in the natural world. Nat Chem Biol 2007, 3(7):408-414.

2. Unsicker SB, Kunert G, Gershenzon J: Protective perfumes: the role of vegetative volatiles in plant defense against herbivores. Curr Opin Plant Biol 2009, 12(4):479-485.

3. Dicke M, van Loon JJA: Multitrophic effects of herbivore-induced plant volatiles in an evolutionary context. Entomol Exp Appl 2000, 97(3):237-249.

4. Dicke M, Baldwin IT: The evolutionary context for herbivore-induced plant volatiles: beyond the 'cry for help'. Trends Plant Sci 2010, 15(3):167-175.

5. Turlings TC, Tumlinson JH, Lewis WJ: Exploitation of herbivore-induced plant odors by host-seeking parasitic wasps. Science 1990, 250(4985):1251-1253. 
6. Van Poecke RMP, Posthumus MA, Dicke M: Herbivore-induced volatile production by Arabidopsis thaliana leads to attraction of the parasitoid Cotesia rubecula: Chemical, behavioral, and gene-expression analysis. J Chem Ecol 2001, 27(10):1911-1928.

7. Clavijo Mccormick A, Irmisch S, Reinecke A, Boeckler GA, Veit D, Reichelt M Hansson BS, Gershenzon J, KÖLIner TG, Unsicker SB: Herbivore-induced volatile emission in black poplar: regulation and role in attracting herbivore enemies. Plant Cell Environ 2014, 37(8):1909-1923.

8. Bernasconi ML, Turlings TCJ, Ambrosetti L, Bassetti P, Dorn S: Herbivoreinduced emissions of maize volatiles repel the corn leaf aphid, Rhopalosiphum maidis. Entomol Exp Appl 1998, 87(2):133-142.

9. Kessler A, Baldwin IT: Defensive function of herbivore-induced plant volatile emissions in nature. Science 2001, 291(5511):2141-2144.

10. Irmisch S, Clavijo McCormick A, Boeckler GA, Schmidt A, Reichelt M, Schneider B, Block K, Schnitzler J-P, Gershenzon J, Unsicker SB, Kollner TG: Two herbivore-induced cytochrome P450 enzymes CYP79D6 and CYP79D7 catalyze the formation of volatile aldoximes involved in poplar defense. Plant Cell 2013, 25(11):4737-4754.

11. Degenhardt J, Kollner TG, Gershenzon J: Monoterpene and sesquiterpene synthases and the origin of terpene skeletal diversity in plants. Phytochemistry 2009, 70(15-16):1621-1637.

12. Chen F, Tholl D, Bohlmann J, Pichersky E: The family of terpene synthases in plants: a mid-size family of genes for specialized metabolism that is highly diversified throughout the kingdom. Plant J 2011, 66(1):212-229.

13. Bohlmann J, Meyer-Gauen G, Croteau R: Plant terpenoid synthases: Molecular biology and phylogenetic analysis. P Natl Acad Sci USA 1998, 95(8):4126-4133.

14. Li GL, Kollner TG, Yin YB, Jiang YF, Chen H, Xu Y, Gershenzon J, Pichersky E, Chen F: Nonseed plant Selaginella moellendorfii has both seed plant and microbial types of terpene synthases. P Natl Acad Sci USA 2012, 109(50):20774-20774.

15. Pare PW, Tumlinson JH: De novo biosynthesis of volatiles induced by insect herbivory in cotton plants. Plant Physiol 1997, 114(4):1161-1167.

16. Bleeker PM, Mirabella R, Diergaarde PJ, VanDoorn A, Tissier A, Kant MR, Prins M, de Vos M, Haring MA, Schuurink RC: Improved herbivore resistance in cultivated tomato with the sesquiterpene biosynthetic pathway from a wild relative. Proc Natl Acad Sci U S A 2012, 109(49):20124-20129.

17. Aharoni A, Giri AP, Deuerlein S, Griepink F, de Kogel WJ, Verstappen FWA, Verhoeven HA, Jongsma MA, Schwab W, Bouwmeester HJ: Terpenoid metabolism in wild-type and transgenic Arabidopsis plants. Plant Cell 2003, 15(12):2866-2884.

18. Dicke M, Sabelis M, Takabayashi J, Bruin J, Posthumus M: Plant strategies of manipulating predatorprey interactions through allelochemicals: Prospects for application in pest control. J Chem Ecol 1990, 16(11):3091-3118.

19. Schnee C, Kollner TG, Held M, Turlings TCJ, Gershenzon J, Degenhardt J: The products of a single maize sesquiterpene synthase form a volatile defense signal that attracts natural enemies of maize herbivores. $P$ Natl Acad Sci USA 2006, 103(4):1129-1134.

20. Arimura G, Huber DPW, Bohlmann J: Forest tent caterpillars (Malacosoma disstria) induce local and systemic diurnal emissions of terpenoid volatiles in hybrid poplar (Populus trichocarpa $\mathrm{x}$ deltoides): CDNA cloning, functional characterization, and patterns of gene expression of (-)-germacrene D synthase, PtdTPS1. Plant J 2004, 37(4):603-616.

21. Danner H, Boeckler GA, Irmisch S, Yuan JS, Chen F, Gershenzon J, Unsicker SB, Kollner TG: Four terpene synthases produce major compounds of the gypsy moth feeding-induced volatile blend of Populus trichocarpa. Phytochemistry 2011, 72(9):897-908.

22. Miller B, Oschinski C, Zimmer W: First isolation of an isoprene synthase gene from poplar and successful expression of the gene in Escherichia coli. Planta 2001, 213(3):483-487.

23. Tuskan GA, DiFazio S, Jansson S, Bohlmann J, Grigoriev I, Hellsten U, Putnam N, Ralph S, Rombauts S, Salamov A, Schein J, Sterck L, Aerts A, Bhalerao RR, Bhalerao RP, Blaudez D, Boerjan W, Brun A, Brunner A, Busov V, Campbell M, Carlson J, Chalot M, Chapman J, Chen GL, Cooper D, Coutinho PM, Couturier J, Covert S, Cronk Q, et al: The genome of black cottonwood, Populus trichocarpa (Torr. \& Gray). Science 2006, 313(5793):1596-1604.

24. Starks CM, Back KW, Chappell J, Noel JP: Structural basis for cyclic terpene biosynthesis by tobacco 5-epi-aristolochene synthase. Science 1997, 277(5333):1815-1820.

25. de Kraker JW, Franssen MCR, de Groot A, Konig WA, Bouwmeester HJ: (+)-Germacrene A biosynthesis - The committed step in the biosynthesis of bitter sesquiterpene lactones in chicory. Plant Physiol 1998, 117(4):1381-1392.
26. Cornwell CP, Reddy N, Leach DN, Wyllie SG: Hydrolysis of hedycaryol: the origin of the eudesmols in the Myrtaceae. Flavour Frag J 2000, 15(6):421-431.

27. Orians C: Herbivores, vascular pathways, and systemic induction: Facts and artifacts. J Chem Ecol 2005, 31(10):2231-2242.

28. Frost CJ, Appel HM, Carlson JE, De Moraes CM, Mescher MC, Schultz JC: Within-plant signalling via volatiles overcomes vascular constraints on systemic signalling and primes responses against herbivores. Ecol Lett 2007, 10(6):490-498.

29. Dicke M, van Loon JJA, Soler R: Chemical complexity of volatiles from plants induced by multiple attack. Nat Chem Biol 2009, 5(5):317-324.

30. Erb M, Meldau S, Howe GA: Role of phytohormones in insect-specific plant reactions. Trends Plant Sci 2012, 17(5):250-259.

31. Wasternack C: Jasmonates: An update on biosynthesis, signal transduction and action in plant stress response, growth and development. Ann Bot-London 2007, 100(4):681-697.

32. Aubourg S, Lecharny A, Bohlmann J: Genomic analysis of the terpenoid synthase (AtTPS) gene family of Arabidopsis thaliana. Mol Genet Genomics 2002, 267(6):730-745.

33. Goff SA: A draft sequence of the rice genome (Oryza sativa L. ssp. japonica) (April, pg 92, 2002). Science 2005, 309(5736):879-879.

34. Paterson AH, Bowers JE, Bruggmann R, Dubchak I, Grimwood J, Gundlach H, Haberer G, Hellsten U, Mitros T, Poliakov A, Schmutz J, Spannagl M, Tang HB, Wang XY, Wicker T, Bharti AK, Chapman J, Feltus FA, Gowik U, Grigoriev IV, Lyons E, Maher CA, Martis M, Narechania A, Otillar RP, Penning BW, Salamov AA, Wang Y, Zhang LF, Carpita NC, et al: The Sorghum bicolor genome and the diversification of grasses. Nature 2009, 457(7229):551-556.

35. Falara V, Akhtar TA, Nguyen TTH, Spyropoulou EA, Bleeker PM, Schauvinhold I, Matsuba Y, Bonini ME, Schilmiller AL, Last RL, Schuurink RC, Pichersky E: The tomato terpene synthase gene family. Plant Physiol 2011, 157(2):770-789.

36. Nieuwenhuizen NJ, Green SA, Chen XY, Bailleul EJD, Matich AJ, Wang MY, Atkinson RG: Functional genomics reveals that a compact terpene synthase gene family can account for terpene volatile production in apple. Plant Physiol 2013, 161(2):787-804.

37. Keeling Cl, Dullat HK, Yuen M, Ralph SG, Jancsik S, Bohlmann J: Identification and functional characterization of monofunctional ent-copalyl diphosphate and ent-kaurene synthases in white spruce reveal different patterns for diterpene synthase evolution for primary and secondary metabolism in gymnosperms. Plant Physiol 2010, 152(3):1197-1208.

38. Martin DM, Aubourg S, Schouwey MB, Daviet L, Schalk M, Toub O, Lund ST, Bohlmann J: Functional annotation, genome organization and phylogeny of the grapevine (Vitis vinifera) terpene synthase gene family based on genome assembly, FLCDNA cloning, and enzyme assays. BMC Plant Biol 2010, 10:226

39. Knudsen JT, Tollsten $L$ : Trends in floral scent chemistry in pollination syndromes - floral scent composition in moth-pollinated taxa. Bot I Linn Soc 1993, 113(3):263-284

40. Loughrin JH, Manukian A, Heath RR, Turlings TCJ, Tumlinson JH: Diurnal cycle of emission of induced volatile terpenoids herbivore-injured cotton plants. Proc Natl Acad Sci U S A 1994, 91(25):11836-11840.

41. Fäldt J, Arimura G-i, Gershenzon J, Takabayashi J, Bohlmann J: Functional identification of AtTPS03 as (E)-B-ocimene synthase: a monoterpene synthase catalyzing jasmonate- and wound-induced volatile formation in Arabidopsis thaliana. Planta 2003, 216(5):745-751.

42. Irmisch S, Krause ST, Kunert G, Gershenzon J, Degenhardt J, Kollner TG: The organ-specific expression of terpene synthase genes contributes to the terpene hydrocarbon composition of chamomile essential oils. BMC Plant Biol 2012, 12:84

43. Shimoda T, Nishihara M, Ozawa R, Takabayashi J, Arimura G: The effect of genetically enriched $(E)$-beta-ocimene and the role of floral scent in the attraction of the predatory mite Phytoseiulus persimilis to spider miteinduced volatile blends of torenia. New Phytol 2012, 193(4):1009-1021.

44. Arimura G, Ozawa R, Shimoda T, Nishioka T, Boland W, Takabayashi J: Herbivory-induced volatiles elicit defence genes in lima bean leaves. Nature 2000, 406(6795):512-515.

45. Arimura G, Ozawa R, Nishioka T, Boland W, Koch T, Kuhnemann F, Takabayashi J: Herbivore-induced volatiles induce the emission of ethylene in neighboring lima bean plants. Plant J 2002, 29(1):87-98.

46. Hopke J, Donath J, Blechert S, Boland W: Herbivore-induced volatiles - the emission of acyclic homoterpenes from leaves of phaseolus-lunatus and zea-mays can be triggered by a beta-glucosidase and jasmonic acid. Febs Lett 1994, 352(2):146-150. 
47. Ament K, Kant MR, Sabelis MW, Haring MA, Schuurink RC: Jasmonic acid is a key regulator of spider mite-induced volatile terpenoid and methyl salicylate emission in tomato. Plant Physiol 2004, 135(4):2025-2037.

48. Kant MR, Ament K, Sabelis MW, Haring MA, Schuurink RC: Differential timing of spider mite-induced direct and indirect defenses in tomato plants. Plant Physiol 2004, 135(1):483-495.

49. Kappers IF, Aharoni A, van Herpen TWJM, Luckerhoff LLP, Dicke M, Bouwmeester HJ: Genetic engineering of terpenoid metabolism attracts, bodyguards to Arabidopsis. Science 2005, 309(5743):2070-2072.

50. Kollner TG, Held M, Lenk C, Hiltpold I, Turlings TCJ, Gershenzon J, Degenhardt J: A maize (E)-beta-caryophyllene synthase implicated in indirect defense responses against herbivores is not expressed in most American maize varieties. Plant Cell 2008, 20(2):482-494.

51. Facchini PJ, Chappell J: Gene family for an elicitor-induced sesquiterpene cyclase in tobacco. Proc Natl Acad Sci U S A 1992, 89(22):11088-11092.

52. Back K, Chappell J: Cloning and bacterial expression of a sesquiterpene cyclase from hyoscyamus-muticus and its molecular comparison to related terpene cyclases. J Biol Chem 1995, 270(13):7375-7381.

53. Chen $X Y$, Chen $Y$, Heinstein $P$, Davisson VJ: Cloning, expression, and characterization of (+)-delta-cadinene synthase: A catalyst for cotton phytoalexin biosynthesis. Arch Biochem Biophys 1995, 324(2):255-266.

54. Hammerschmidt R: Phytoalexins: What have we learned after 60 years? Annu Rev Phytopathol 1999, 37:285-306.

55. Huffaker A, Kaplan F, Vaughan MM, Dafoe NJ, Ni XZ, Rocca JR, Alborn HT, Teal PEA, Schmelz EA: Novel acidic sesquiterpenoids constitute a dominant class of pathogen-induced phytoalexins in maize. Plant Physiol 2011, 156(4):2082-2097.

56. de Kraker JW, Franssen MCR, Dalm MCF, de Groot A, Bouwmeester HJ: Biosynthesis of germacrene A carboxylic acid in chicory roots. Demonstration of a cytochrome P450 (+)-germacrene A hydroxylase and NADP (+)-dependent sesquiterpenoid dehydrogenase(s) involved in sesquiterpene lactone biosynthesis. Plant Physiol 2001, 125(4):1930-1940.

57. de Kraker JW, Franssen MCR, Joerink M, de Groot A, Bouwmeester HJ: Biosynthesis of costunolide, dihydrocostunolide, and leucodin. Demonstration of cytochrome P450-catalyzed formation of the lactone ring present in sesquiterpene lactones of chicory. Plant Physiol 2002, 129(1):257-268.

58. Ramirez AM, Saillard N, Yang T, Franssen MCR, Bouwmeester HJ, Jongsma MA: Biosynthesis of sesquiterpene lactones in pyrethrum (Tanacetum cinerariifolium). Plos One 2013, 8(5):e65030.

59. Chen F, Ro DK, Petri J, Gershenzon J, Bohlmann J, Pichersky E, Tholl D: Characterization of a root-specific Arabidopsis terpene synthase responsible for the formation of the volatile monoterpene 1,8-cineole. Plant Physiol 2004, 135(4):1956-1966.

60. Tholl D, Chen F, Petri J, Gershenzon J, Pichersky E: Two sesquiterpene synthases are responsible for the complex mixture of sesquiterpenes emitted from Arabidopsis flowers. Plant J 2005, 42(5):757-771.

61. Kollner TG, Lenk C, Schnee C, Kopke S, Lindemann P, Gershenzon J, Degenhardt J: Localization of sesquiterpene formation and emission in maize leaves after herbivore damage. BMC Plant Biol 2013, 13:15.

62. Farmer $\mathrm{EE}$, Almeras $\mathrm{E}$, Krishnamurthy $\mathrm{V}$ : Jasmonates and related oxylipins in plant responses to pathogenesis and herbivory. Curr Opin Plant Biol 2003, 6(4):372-378.

63. Ralph S, Oddy C, Cooper D, Yueh H, Jancsik S, Kolosova N, Philippe RN, Aeschliman D, White R, Huber D, Ritland CE, Benoit F, Rigby T, Nantel A, Butterfield YS, Kirkpatrick R, Chun E, Liu J, Palmquist D, Wynhoven B, Stott J, Yang G, Barber S, Holt RA, Siddiqui A, Jones SJ, Marra MA, Ellis BE, Douglas CJ, Ritland K, et al: Genomics of hybrid poplar (Populus trichocarpa $\mathrm{x}$ deltoides) interacting with forest tent caterpillars (Malacosoma disstria): normalized and full-length cDNA libraries, expressed sequence tags, and a CDNA microarray for the study of insect-induced defences in poplar. Mol Ecol 2006, 15(5):1275-1297.

64. Major IT, Constabel CP: Shoot-root defense signaling and activation of root defense by leaf damage in poplar. Can J Bot 2007, 85(12):1171-1181.

65. Tholl D, Boland W, Hansel A, Loreto F, Rose USR, Schnitzler JP: Practical approaches to plant volatile analysis. Plant J 2006, 45(4):540-560.

66. Ramirez-Carvajal GA, Morse AM, Davis JM: Transcript profiles of the cytokinin response regulator gene family in Populus imply diverse roles in plant development. New Phytol 2008, 177(1):77-89.
67. Tamura K, Peterson D, Peterson N, Stecher G, Nei M, Kumar S: MEGA5: molecular evolutionary genetics analysis using maximum likelihood, evolutionary distance, and maximum parsimony methods. Mol Biol Evol 2011, 28(10):2731-2739.

68. Kramell R, Schmidt J, Schneider G, Sembdner G, Schreiber K: Synthesis of $\mathrm{N}$-(Jasmonoyl) amino acid conjugates. Tetrahedron 1988, 44(18):5791-5807.

69. Crawley MJ: Statistical Computing. Chichester: John Wiley \& Sons Ltd; 2002.

doi:10.1186/s12870-014-0270-y

Cite this article as: Irmisch et al:: Terpene synthases and their contribution to herbivore-induced volatile emission in western balsam poplar (Populus trichocarpa). BMC Plant Biology 2014 14:270.

\section{Submit your next manuscript to BioMed Central and take full advantage of:}

- Convenient online submission

- Thorough peer review

- No space constraints or color figure charges

- Immediate publication on acceptance

- Inclusion in PubMed, CAS, Scopus and Google Scholar

- Research which is freely available for redistribution

Submit your manuscript at www.biomedcentral.com/submit
C) BioMed Central 